\title{
Transcriptome meta-analysis reveals a central role for sex steroids in the degeneration of hippocampal neurons in Alzheimer's disease
}

\author{
Jessica M Winkler and Howard S Fox
}

\begin{abstract}
Background: Alzheimer's disease is the most prevalent form of dementia. While a number of transcriptomic studies have been performed on the brains of Alzheimer's specimens, no clear picture has emerged on the basis of neuronal transcriptional alterations linked to the disease. Therefore we performed a meta-analysis of studies comparing hippocampal neurons in Alzheimer's disease to controls.

Results: Homeostatic processes, encompassing control of gene expression, apoptosis, and protein synthesis, were identified as disrupted during Alzheimer's disease. Focusing on the genes carrying out these functions, a protein-protein interaction network was produced for graph theory and cluster exploration. This approach identified the androgen and estrogen receptors as key components and regulators of the disrupted homeostatic processes.

Conclusions: Our systems biology approach was able to identify the importance of the androgen and estrogen receptors in not only homeostatic cellular processes but also the role of other highly central genes in Alzheimer's neuronal dysfunction. This is important due to the controversies and current work concerning hormone replacement therapy in postmenopausal women, and possibly men, as preventative approaches to ward off this neurodegenerative disorder.
\end{abstract}

Keywords: Androgen receptor, Estrogen receptor, Graph theory, Hippocampus, Neurodegeneration

\section{Background}

Alzheimer's disease (AD) is of high interest in neurodegenerative research because an increasing rate of occurrence and lack of effective treatment or prevention. By 2050, 1 in 85 people globally are predicted to suffer from $\mathrm{AD}$. This increase is thought to be due to the elevation in life expectancy and the resulting growing elderly population [1]. Signs of $A D$ first begin with problems in short term memory progressing to a loss of long term memory and body functions. AD progression continues with increasing loss of memory and faculties ending in death [2]. Brain pathologies, amyloid beta plaques, neurofibrillary tangles and a loss of synaptic connections contribute to the progression [3].

Many AD studies focus on the brain's memory and learning specific area, the hippocampus. The hippocampus,

\footnotetext{
* Correspondence: hfox@unmc.edu

Department of Pharmacology and Experimental Neuroscience, University of Nebraska Medical Center, Omaha, NE 68198, USA
}

which functions in consolidation of new memories, emotional responses, navigation, and spatial orientation, is affected early in AD. The functions of the hippocampus are progressively disrupted, and $\mathrm{AD}$ neuropathology can be prominent in the hippocampus [4]. In order to obtain molecular clues to the etiology and pathogenesis of $\mathrm{AD}$, investigators have performed a number of gene expression profiling studies on the hippocampus of $\mathrm{AD}$ and control brains [5-13]. Yet synthesizing the information from these different studies has been problematic. One of the reasons for this is the variability that stems from numerous sources during biological experimentation. Four of these are prominent in such studies on AD: the use of post mortem human samples, potential differences in the brain regions and cellular composition of examined specimens, carrying out experimentation in different labs, and the generation of high density "omic" data.

While microarray analysis has grown in popularity since its introduction 20 years ago many limitations have been found in both array and protocol design, including 
batch effect, uniform hybridization conditions for the probes, and ratio compression. However being a rather mature technology such problems are well known and these effects can be taken into consideration in the data analysis methods.

In our study we utilized a meta-analysis technique. Meta-analysis refers to the statistical methods for combining data from similar biological studies. Microarray datasets are excellent meta-analysis candidates due to the high use and deposit in publically accessible data banks, complete with information on experimental conduct. Advantages of meta-analysis include an increase in precision due to increased effect size, control for between-study variation and overcoming bias of individual studies [14,15]. As different microarray platforms can have different limitations as well as in some cases yield different results, we designed our study design by choosing independent experiments that use the same platform. By doing so the technical specifics and probe sequences are the identical. Furthermore we used a non-parametric permutation test based on ranks instead of gene expression values themselves to capture statistically significant genes that change between the conditions [15-17].

These differentially changed genes were then assessed through a systems biology approach. Systems biology can have many applications; we refer to its use to obtain biological information through utilizing whole-genome transcriptome analysis to assess networks and their interactions through the use of computational methods. Here we report that a meta-analysis of specific microarray datasets investigating $\mathrm{AD}$, followed by a systems biology approach, yields unique insights into $\mathrm{AD}$ etiopathogenesis.

\section{Results}

\section{Dataset gathering, ensemble mapping and expression} analysis

Studies on gene array expression profiling for AD have examined different stages of disease and different areas of the brain. One important aspect of such studies on the brain is that the dissected tissue contains neurons, as well as glia (astrocytes, oligodendrocytes and microglia) and other cell types such as endothelial cells and pericytes. Gene expression in cell-types of interest within specific regions of the brain can be studied through microdissection, usually through laser capture. The functional pathology in $\mathrm{AD}$ is primarily linked to the neurons themselves. Given the predominance of the hippocampus in the initiation and progression of the disease, we searched the Gene Expression Omnibus (GEO) for transcriptional profiling studies on hippocampus in AD in which neurons had been microdissected. Two such studies were identified in which neurons were laser captured from the CA1 region of the hippocampus (Table 1) [5-7], totaling 17 arrays from $\mathrm{AD}$ cases and 21 arrays from controls. Both studies utilized Affymetrix Human Genome U133 Plus 2.0 GeneChip arrays; no such studies have been performed on other platforms or other technologies such as SAGE or RNA-Seq.

Most microarray analysis occurs by mapping to platform specific "probe" or "probe set" IDs with manufacturersupplied annotations. This approach poses three problems: errors and irrelevancies, multiple IDs for a single gene, and combining multiple microarray platforms. While the latter does not apply to this study, the others pose a serious problem to accurate data analysis. The Affymetrix platform utilizes multiple probes assembled into probe sets to define the expression of genes. Using the GeneMapper program we deconvoluted the probe sets and remapped the probes to a singular identifier for known genes updated to our current understanding of the human genome. Fitting our criteria, we choose Ensemble Gene (ENSG) IDs for re-mapping individual probes from the probe sets to gene IDs, and reassembling the correctly mapping probes into new sets resulting in probe sets corresponding to 20,172 ENSG IDs.

After remapping, we then evaluated the presence of differentially expressed genes (DEGs) between $\mathrm{AD}$ and controls in each separate experiment. We utilized Rank Product analysis, a non-parametric method based on geometric mean of fold changes, to produce a fold-change, statistics and a ranking for each ID. Importantly Rank Product is efficacious for both single studies as well as meta-analysis. We then used the rankings to construct a Correspondence At the Top (CAT) plot, measuring proportions of DEGs in common between the two studies [19]. The CAT plot revealed that there was very little in common between the two studies (Figure 1), unfortunately not an infrequent finding, especially when each study itself has a limited sample size. Therefore we combined data for meta-analysis, again using Rank Product analysis, in order to obtain a clearer picture of the transcriptomic changes in neurons in AD.

\section{Meta-analysis and bioinformatics of hippocampal neurons in $A D$ reveals dysfunction in homeostatic processes}

Utilizing a false discovery rate of $<0.05$, we found that 2126 genes were differentially regulated in AD hippocampal neurons compared to controls when combining the two studies (Additional file 1: Table S1). We next wanted to compare the DEGs with genes that have been identified as expressed in CA1 hippocampal neurons. Using the rat CA1 hippocampal cell body transcriptome identified by Cajigas et al. [20], 74.5\% of the DEGs found in the studies we examined from aged brains are indeed known to be expressed in CA1 hippocampal neurons, confirming the efficacy of the microdissection. 
Table 1 GEO datasets used in the meta-analysis

\begin{tabular}{llcccc}
\hline GEO dataset & ADC source of cases & Group description & Braak stage & Age & Brief summary of findings \\
\hline GSE28146 & University of Kentucky & Control & $2.3 \pm 0.4$ & $85.3 \pm 2.7$ & $\begin{array}{c}\text { Down regulation of molecules that stabilize } \\
\text { ryanodine receptor Ca2+ release }\end{array}$ \\
\cline { 3 - 5 } & & Severe AD & $5.8 \pm 0.2$ & $84.0 \pm 4.0$ & Up regulation of vasculature development \\
\hline GSE5281 & $\begin{array}{c}\text { Arizona, Duke University, } \\
\text { Washington University }\end{array}$ & Not AD & $1.2 \pm 0.1$ & $79.6 \pm 2.6$ & Mitochondrial and electron transport dysfunction \\
\cline { 3 - 5 } & & Definite AD & $5.3 \pm 0.2$ & $77.8 \pm 1.8$ & Expression changes of metabolism-related genes \\
\hline
\end{tabular}

ADC Alzheimer's Disease Center. Braak Stage Neuropathological staging according to [18]. Values for Braak stage and Age are mean \pm S.E.M.

To achieve a functional understanding of the DEGs, we then probed their biological function using the Ingenuity Pathway Analysis tool (IPA) which curates biological function based on annotated ontologies. While analysis did not reveal any neuron/brain specific functions, we found an over representation of terms suggesting dysfunctions in core homeostatic pathways: protein synthesis, repression of RNA, and cell death/apoptosis (Table 2). Along with all cell types, regulation of gene expression, the synthesis of proteins and the control of cell death play a detrimental roll in neuron health, survival, and overall brain function. The genes represented by the functional annotation Apoptosis are also found with the genes in the Cell death annotation, and combining these lists resulting in a total of 329 unique genes participating in these homeostatic processes (Additional file 2: Table S2). This led us to the hypothesis that translation, transcription and cell death/ apoptosis are mechanisms through which $\mathrm{AD}$ compromises neuronal integrity. For this reason we chose to further investigate these genes to identify key specific genes to these homeostatic pathways and AD.

\section{Biological network generation of homeostatic process genes utilizing protein-protein interactions}

We next wanted to find which of these genes interacted with each other directly and through other partners,

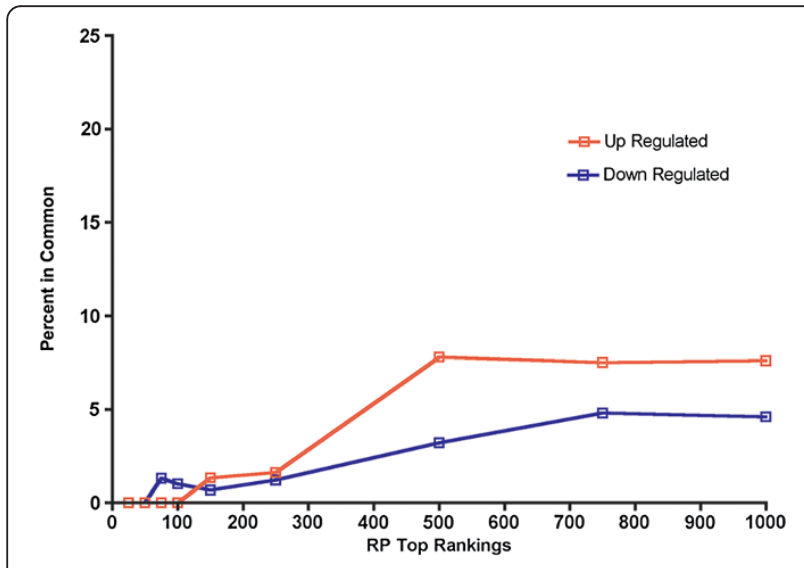

Figure 1 Correspondence at the Top plot. The $x$-axis is top ranking genes based on rank product. The $y$-axis is the percentage of genes in common among between the two studies at each level of ranking, for the upregulated (red) and down regulated (blue) genes. thus building on the gene list by incorporating additional interacting partners that may not have been identified as significantly differentially expressed. Because the protein products of genes do not act alone but rather cooperate with other proteins to perform a function, we assessed the protein-protein interactions (PPIs) of the focal 329 genes. For this we used Genes2Networks, which integrates the data contained in multiple interaction network datasets, enables the user to determine the path length (degree of interaction), and incorporates possible interacting proteins which are not part of the user's original input list. We chose to explore $1^{\text {st }}$ (direct) and $2^{\text {nd }}$ (through another protein) degree PPIs among the protein products of the focal genes to gain complexity without losing specificity of the overall network. The resulting PPI network consisted of 305 nodes and 727 edges (Figure 2). PPI networks hold an immense amount of information not only about individual proteins and pathways but also on directional flow and interconnection of biological functions. In order to understand key protein players within the network, we next employed graph theory modeling for exploration of the large number of proteins within the network.

\section{Identification of central AD genes through graph theory analysis}

We then set out to identify the key genes crucial to the mechanism of the overall interactome of these proteins. Communication within networks is key to their functions as a whole. PPI networks can form hubs and complexes, or show enzymatic relationships. To better understand critical nodes within our PPI networks, we used graph theory for centrality modeling, specifically closeness, eccentricity, and radiality. These measure the network's topology and use individual node proximities in finding highly central nodes. Being highly central to communication of the network highlights the importance of that node in the overall functions characterized [21]. Closeness, eccentricity and radiality are similar but achieved differently mathematically; with radiality and closeness being quite similar with the exception that radiality is based on individual network diameter whereas closeness is not. Each computes the shortest paths between single proteins and all other proteins in the network. By using these three similar yet differently calculated centralities, we can compare 
Table 2 Biologic functional analysis of DEGs

\begin{tabular}{|c|c|c|c|c|c|}
\hline Category & Functions annotation & P-value & Predicted activation state & Regulation z-score & Number of genes \\
\hline Gene expression & Repression of RNA & $9.19 \mathrm{E}-03$ & Increased & 2.617 & 17 \\
\hline Cell death & Cell death & $8.85 \mathrm{E}-03$ & Increased & 2.234 & 291 \\
\hline Cell death & Apoptosis & $2.48 \mathrm{E}-02$ & Increased & 2.168 & 213 \\
\hline Protein synthesis & Synthesis of protein & 4.92E-05 & Decreased & -2.064 & 40 \\
\hline
\end{tabular}

IPA analysis of functions $(p<0.05, z$-score $>|2|)$, with predicted activation state.

node placement between the measurements. This will identify highly central nodes for further investigation.

We utilized CentiScaPe to calculate node centrality values. We restricted our interest into nodes with above average values when comparing closeness, radiality, and eccentricity, terming them as above average nodes (Figure 3). As expected for the networks, closeness and radiality had a linear relationship due to their similar calculations. When comparing closeness and eccentricity, the androgen receptor (AR) and the estrogen receptor alpha (ESR1) stand out as the top two nodes within the network. ESR1 has a greater eccentricity value than AR. This places more proteins in ESR1's proximity suggesting greater role in dictating functional directions within the network. AR has a greater closeness than ESR1 placing AR in proximity of more proteins than ESR1. This suggests AR works more through competition to achieve specific functions. Indeed sex steroids have been implication in $\mathrm{AD}$ pathogenesis [22].

\section{Isolating dense network regions of key AD genes through cluster analysis}

After graph theory analysis, we wanted to better understand the relationships between the PPI network proteins that

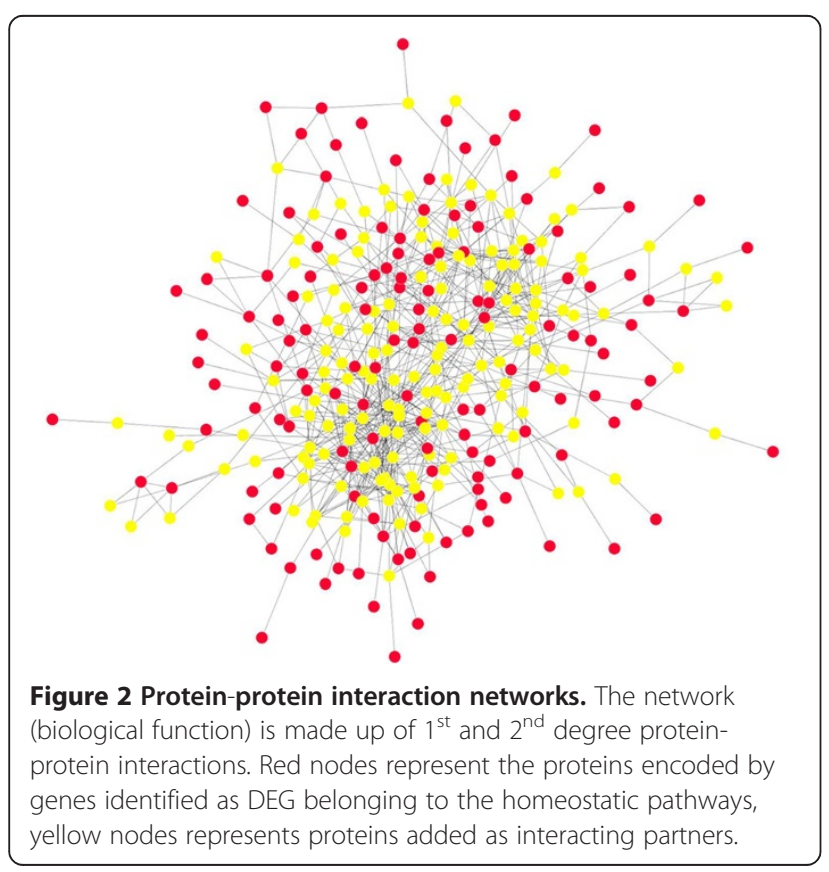

were above average for closeness, radiality, and eccentricity; the 73 genes encoding these proteins were termed highly central genes (Additional file 3: Table S3). Before understanding the interconnection between these genes, we once again examined whether these genes were reported to be expressed in CA1 hippocampal neurons. Indeed $90.4 \%$ of these above average, highly central genes are expressed by these cells [20]. Highly interconnected, dense areas within a network can denote protein clusters or parts of pathways. Using MCODE, we identified five of these dense regions within the network (Figure 4). The first dense region (Figure 4A) contains AR along with transcription factors, including the glucocorticoid receptor (NR3C1), which belongs to the same protein subfamily and group as AR. With the other proteins, such as FOS and NFKB1, this cluster represents a complex of transcription factors. Similarly ESR1 was found in the fourth cluster with other transcription factors including SP1, JUN and STAT3 (Figure 4D). The fifth cluster also identifies transcription factors and a regulator, CREBBP, RELA, and BRCA1 (Figure 4E). The second and third clusters (Figure 4B,C) do not contain any transcription factors, but rather kinases and ligases that carry out signal and degradation pathways. Taken together these clusters indicate that the original first list of genes/proteins contain transcription, degradation, and signaling hubs that regulate the transcription, translation, and cell death/apoptosis in AD.

\section{Corroboration of the selected genes' involvement in AD pathology}

We predicted that the proteins produced during the graph theory and cluster analyses would be integral for $\mathrm{AD}$ dysfunction. To test this, the proteins above centrality averages in the graph theory assessment were used as input for three independent systems biology tools: two propriety databases (IPA and MetaCore), and the publically available database DAVID. These genes were examined for enrichment in "diseases and disorders". Many of the genes had links to cancer for all three databases due to the high amount of experimental data on cancer curated within many databases, still in each case these genes were significantly enriched in pathways for neurodegenerative disorders, specifically AD (Table 3). First for IPA, AD was found to be enriched, as well 

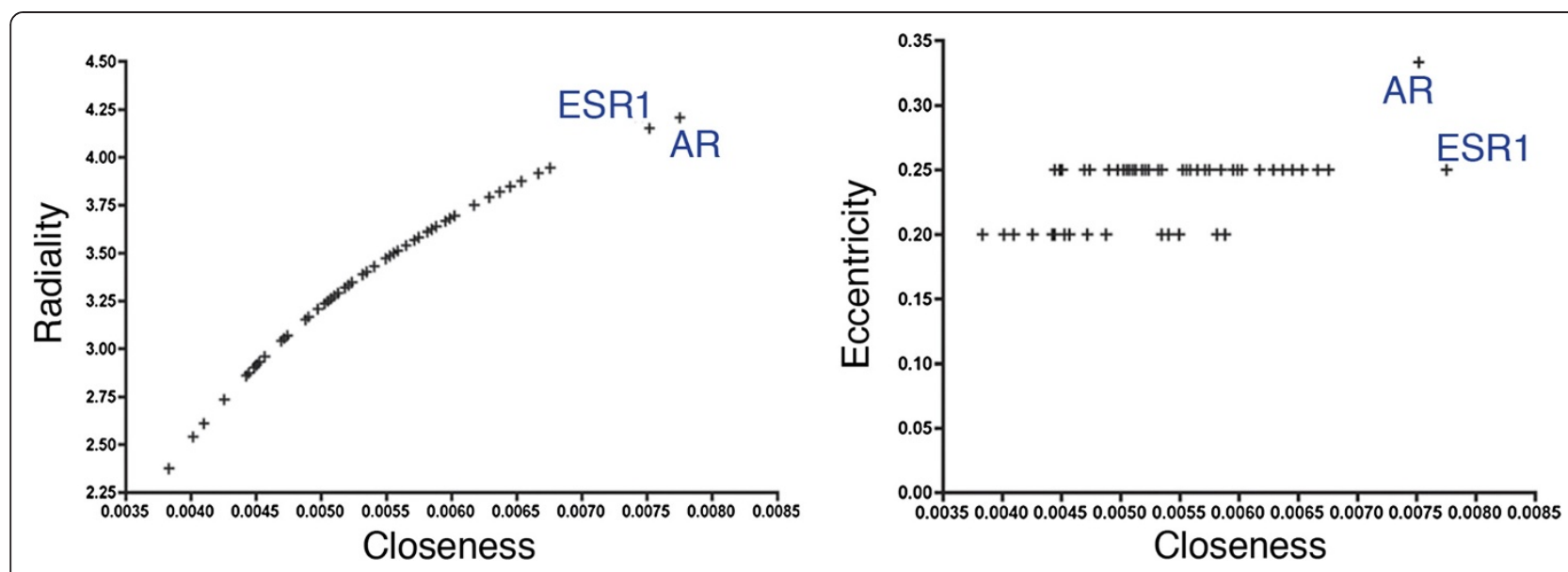

Figure 3 Radiality, eccentricity, and closeness. Closeness ( $X$-axis) is plotted versus Radiality (left) and Eccentricity (right) on the Y-axis. Each axis represents the range of above average values for the centrality measures. The positions of ESR1 and AR are indicated.

as, at lower levels of significance, Parkinson's Disease and Huntington's Disease. The second database, MetaCore, also identified gene enriched for neurodegenerative disease, dementia, and $\mathrm{AD}$, and at a much lower significance Parkinson's Disease. Finally we used DAVID to look for disease ontology enrichment and found AD, and at a lower level of significance, Parkinson's Disease. In all three databases AD ontology had a greater statistical significance than other neurodegenerative disorders such as Parkinson's or Huntington's Disease. While there are indeed similarities in pathways activated to result in neuronal damage and death in neurodegenerative diseases, the greater significance found for $A D$ validates the role of these genes in the deregulation of transcription, translation, and cell death/apoptosis in CA1 hippocampal neurons affected by AD.

\section{Discussion}

The data in this study highlights the ability of meta-analysis and systems biology approach to help unravel the complexity of AD. When looking specifically at biological functions, $\mathrm{AD}$ disrupts protein synthesis, cell death/ apoptosis, and gene expression through the repression of RNA. These processes are essential for the health of neurons. A recent meta-analysis study for AD was conducting using 100 publically available microarray datasets from hippocampus brain samples [23]. While this paper focused more on AD progression, similar changes were identified in the cellular functions of protein and gene expression regulations. Taken together with our study this suggests that $\mathrm{AD}$ affects very important yet basic cellular, homeostatic processes such as the ones identified here: transcription, translation, and cell death/apoptosis.
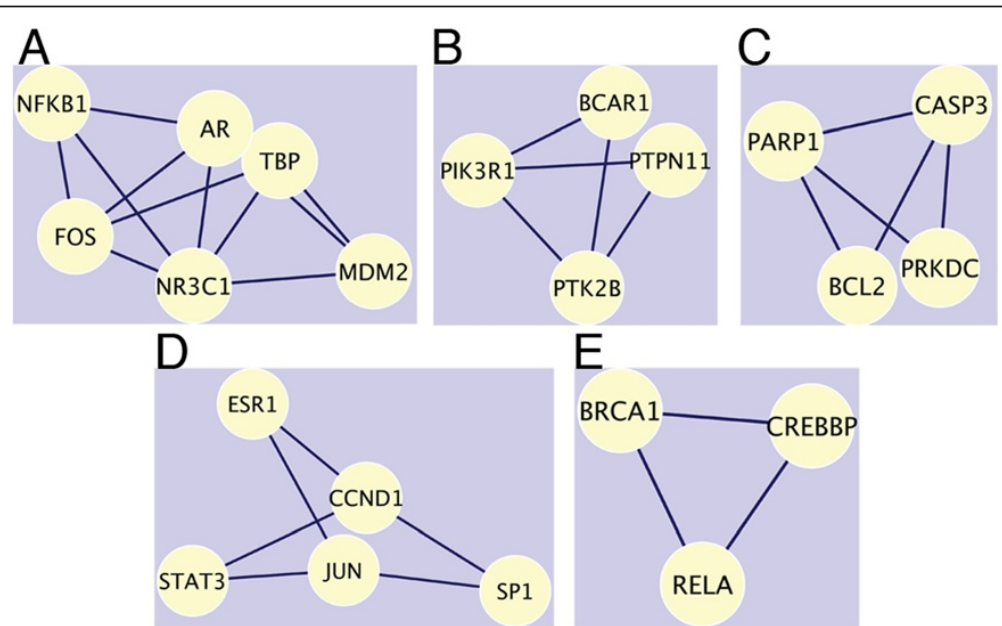

Figure 4 MCODE complexes. Clusters A, D, and $\mathbf{E}$ contain transcription factors, with AR present in Cluster $\mathbf{A}$ and ESR1 in Cluster D. Clusters B and C contain kinases and ligases but not transcription factors. Yellow nodes represent proteins, indicated by their symbols, and interconnections by black edges. 
Table 3 Biologic functional analysis of highly central genes

\begin{tabular}{ccc}
\hline Bioinformatics Platform & Disease & p-value \\
\hline IPA & Alzheimer's Disease & $4.40 \mathrm{E}-08$ \\
& Parkinson's Disease & $2.88 \mathrm{E}-04$ \\
& Huntington's Disease & $1.28 \mathrm{E}-03$ \\
MetaCore & Neurodegenerative Diseases & $4.20 \mathrm{E}-25$ \\
& Dementia & $5.98 \mathrm{E}-24$ \\
& Alzheimer's Disease & $3.30 \mathrm{E}-23$ \\
DAVID & Parkinson's Disease & $2.15 \mathrm{E}-13$ \\
& Alzheimer's Disease & $1.40 \mathrm{E}-03$ \\
& Parkinson's Disease & $1.10 \mathrm{E}-02$ \\
\hline
\end{tabular}

IPA, MetaCore, and DAVID analysis of neurological disease enrichment. The diseases identified were based on the 73 genes that are highly central in the PPI network.

While men and women express both AR and ESR1 receptors, the levels of their ligands, testosterone and estrogen, separate the sexes. ESR1 and estrogen work to promote female characteristics and reproductive maintenance. Besides these huge defining attributes, estrogen works in a variety of genomic and non-genomic ways. AR and testosterone are important in male development and like estrogens work outside of a sexual role. Both estrogen and testosterone demonstrate neuroprotective qualities and have been implicated in $\mathrm{AD}$ development and progression. Aging causes a decrease in testosterone and estrogen levels, which several studies have linked to an increase incidences of AD.

Many studies focusing on the relationship between estrogen, $\mathrm{AD}$ and the female brain have found that the increase in $\mathrm{AD}$ in women is not due to their increased lifespan [24-33]; the female brain appears to be more vulnerable to $\mathrm{AD}$ pathology. This is also found in the Tg2576, APPswexPS1 and 3xTg-AD triple AD mouse models when females are age-matched to males. Females of all three models display higher $A \beta$ load burden and plaque quantity as compare to the male counterparts. [34-36] Neuroprotective properties come from estrogen's connection with the Bcl2 family in apoptotic pathways [37-41], involved in excitotoxcity [42-47], inflammation $[48,49]$, and oxidative stress $[50,51]$.

The role of menopause and subsequent Hormone or Estrogen Replacement therapy (HRT or ERT) in AD has been part of the experimental discussion. The decreased level of estrogen resulting from menopause is thought to cause a woman's increased vulnerability to AD. Many female $\mathrm{AD}$ patients due indeed have lower than usual estrogen levels and studies have shown that low estrogen increases incidence of AD. Despite these links between estrogen and $\mathrm{AD}$, the results are mixed on the benefits of HRT/ERT for AD development and progression. Most studies suggest that HRT/ERT is beneficial if a long- term regime is adhered to [52-59] and decrease the risk of cognitive dysfunction [60-63] while the other studies are inconclusive on overall benefit [64-73]. The time at which HRT is administered may also affect AD risk. HRT five or more years after menopause may negate its protective role in reducing the risk of developing $A D$ [74]. The truth behind HRT's role in AD may not be discovered until HRT/ERT itself is properly understood, prescribed, and used.

Additional studies linking ESR1 to AD have examined changes in its nuclear versus cytoplasmic subcellular distribution in the hippocampus [75-77], as well as membrane localization leading to estrogen-induced activation of hippocampal glutamate receptors in the absence of glutamate [78]. Furthermore differences between ESR1 alleles correlates with an increased risk for $\mathrm{AD}$ in women with Down syndrome [79]. Finally, in neural cell lines, ESR1 has been linked to neuroprotection [80]. Through the ESR1 specific agonist, propylpyrazole, the receptor's activity has been shown to protect against $A \beta$ accumulation [81] and from glutamate excitotoxicity through ERK signaling and upregulation of Bcl-2 at the gene level $[82,83]$.

Aging men are not exempt from the connection between $\mathrm{AD}$ and sex hormones. As stated earlier both ESR1 and AR are both implicated in AD and it's progression, but the extent of each receptor's role remains unclear $[84,85]$. A similar increased $A D$ risk is associated with low testosterone levels in men. Like estrogen, testosterone has been shown to regulate levels of $A \beta$. However, the blocking of testosterone to estrogen converting enzyme, aromatase, in one study attributes neuroprotection with estrogen alone [86]. However testosterone and AR play their own role in neuroprotection from $A \beta$ accumulation. The male population presents the opposite model as a posed to the female population; sufferers of prostate cancer undergo anti-androgen therapy causing a reduction in testosterone levels. Studies in these patients have shown increased levels of plasma $A \beta[87,88]$.

$A R$ and ESR1 are known to have functional importance in AD; this was a topic of discussion well before our study or the studies used within our study were conceived. Our meta-analysis and systems biology analyses were capable of identifying these "chains" of $\mathrm{AD}$ changing genes surrounding AR and ESR1. Our findings integrate well into and help fill current gaps in our knowledge on $\mathrm{AD}$.

By focusing on differentially expressed genes, their protein-binding partners of their products, and utilizing graph theory, we were able to broaden our knowledge of AD's pathogenesis. Proteins/genes do not live in a vacuum and so changes in expression affects the ability of other proteins/genes to function. Available levels of proteins can 
cause competition between binding partners, which then can in turn shunt pathways to be activated, inhibited or perhaps balance out. The clusters for each sub network are based on highly interconnected areas, which represent protein complexes. The level and variety of proteins comprising the complex can give the individual complex a "fingerprint" that elicits various functions.

\section{Conclusions}

Meta-analysis and systems biology approaches allowed us a unique view of hippocampal neuron-specific transcriptomic analysis in $\mathrm{AD}$. By using meta-analysis combining data from independent studies, we were able to identify deregulation of genes that participate in transcription, translation, and cell death/apoptosis in CA1 hippocampal neurons from AD patients. Further investigation of these genes and their interactions led to the identification of genes important to the overall mechanism of the deregulated homeostatic processes. The two centrally highest genes, AR and ESR1, and their role in $\mathrm{AD}$ pathology are under examination clinically and in experimental models. Use of a final method based on cluster density, reduced our focus to a smaller set of genes. Based on three independent bioinformatics tools, these genes are enriched for processes involved in AD pathophysiology. Taken together with our initial findings these genes play a role in AD through dysregulation of the basic homeostatic processes of transcription, translation, and cell death/apoptosis.

\section{Methods}

\section{GEO data retrieval, microarray normalization and ensemble mapping}

The Gene Expression Omnibus (GEO) (http://www.ncbi. nlm.nih.gov/geo/) is a public repository of various genetic high through put data sources. Microarray data sets for different chips types are deposited with extensive experimental design and information and with normalized and/or raw data. We set our experimental criteria specific to postmortem human hippocampal samples analyzed using an Affymetrix platform. Our search obtained two GEO data sets, GSE5281 and GSE28146 (we only utilized the arrays from severe AD patients from this study), which contained CA1 region specific individual hippocampal neurons data. The appropriate control and AD raw CEL files were downloaded from the GEO site. Next the CEL files were read into the $\mathrm{R}$ programming console using the affy package [89] (this and other R-based tools were obtained from the open source Bioconductor bioinformatics software, http://www.bioconductor.org). In the uploading process CDF files were associated with the microarrays through the GeneMapper package. Downloaded from GATExplorer [89-91] GeneMapper (http://bioinfow.dep.usal.es/xgate/mapping/mapping.php) includes the sets of unambiguous probes that map to each specific Ensemble Gene ID (ENSG ID). Also through affy package, the intensity files were normalized using Robust Multichip Average, RMA. A three-step process, RMA performs a background adjustment, quantile normalization and final summarization [92].

\section{Ethics}

The data utilized were obtained from a research repository databank (GEO), involves decedents, contains no personal identifiers, and the authors had no role in the collection or storage of these data.

\section{RankProd}

The R RankProd package contains functions for differential gene expression analysis of microarrays based on a nonparametric statistic [93]. RankProd identifies genes that are consistently highly ranked amount a list of genes. Since the method exploits the rank of genes not the actual expression value, it can be flexibly applied to many different questions, such as identifying genes.

It assumes that under the null hypothesis the order of genes are random and statistically probabilities are based on the probability of a particular ranking. Rank product is the multiplication of these probabilities. RankProd produces a list of up- or down- regulated genes with false discovery rate (FDR). RankProd also has the ability to combine data sets from different origins into a single meta-analysis to increase the power of the identification [93].

\section{Ingenuity pathway analysis}

IPA is commercially available software (Ingenuity Systems, Inc., Redwood City, CA) for several types of analysis and is popular in a variety of biological fields/studies. IPA utilizes a large, well-designed knowledge base and enables functional, canonical pathway and network analysis. IPA uses its knowledge base to better understand how the data fit with the curated functional, canonical pathway, and interaction network information. We utilized the Functional Analysis tool to identify the biological functions and/or diseases that were most significant to the data set. Molecules from the dataset were associated with biological functions and/or diseases in the Ingenuity Knowledge Base were considered for the analysis. Right-tailed Fisher's exact test was used to calculate a p-value determining the probability that each biological function and/or disease assigned to that data set is due to chance alone.

\section{Genes2Networks}

A publically available bioinformatics database, Genes2 Networks (http://actin.pharm.mssm.edu/genes2networks/) 
is hub of databases used to find relationships between genes and proteins from seed lists [94]. Predictions of genes or proteins that may play crucial roles in pathways or protein complexes are supplemented to the seed list. Gene2Networks calculates a Z statistic using a binomial proportions test on the significance of a supplemented protein in the output sub network.

\section{Cytoscape plugins}

Cytoscape, a popular publically available bioinformatics package (http://www.cytoscape.org), represents networks, with biological entities as nodes and biological interactions as edges between nodes [95]. Plugins are designed to run several types of analysis. Before plugins are applied all satellite networks are removed leaving a single interconnected network of nodes. This study uses two such plugins, CentiScaPe and MCODE.

\section{CentiScaPe}

CentiScaPe is an interface to analyze topology of proteinprotein interaction networks [96]. CentiScaPe uses a variety of graph theory centrality measurements to determine and develop sub networks. In this study we used the following:

\section{Eccentricity}

Eccentricity computes the shortest paths between a single node and all other nodes in the graph. Next the longest shortest path is chosen and the reciprocal is taken. Higher value represent nodes that have the shortest paths, meaning all other nodes are in its proximity. All other proteins within the network easily reach proteins with high eccentricity. Thus, a protein with high eccentricity dictates functional directions, but also is subjected to functional control by binding partners. On the opposite end, a low eccentricity suggests a peripheral functional role.

\section{Closeness}

Closeness computes the shortest path between a single node and all other nodes. The summation is taken of the shortest paths and the reciprocal is taken. Nodes with high closeness are in close proximity to all other nodes in the network. If the closeness measure is low, all other nodes are distant from this node. Closeness measurements can also reflect few nodes that are very close or distant from a specific node. Therefore closeness is not specific to the nature of the node couples and should be compared with eccentricity and radiality. In relation to PPI networks, closeness can represent functionally and points of competition between proteins.

\section{Radiality}

Radiality is calculated similarly to closeness, but subtracts the diameter of the graph from each path. This value is then summated and finally divided by the number of nodes minus 1. Short paths have high radiality values where as long paths have low values. With respect to the diameter high radiality nodes are closer to other nodes. In PPI networks radiality can represent functional relevancy between a single protein and other proteins and functional directional control.

\section{MCODE}

Another plugin used Molecular Complex Detection, MCODE, formulates clusters within a network [97]. MCODE, a theoretic clustering algorithm, identifies densely connected areas in large protein-protein interaction networks that could suggest protein complexes. MCODE is built on vertex weighting by local neighborhood density and outward crossing from a locally dense protein isolating the dense regions according to user specific parameters. [97] MCODEv1.32 was used for cluster identification among the proteins with the two sub networks.

\section{MetaCore}

MetaCore is commercially available software (GeneGo, Thompson Reuters, New York, NY) for functional analysis of high throughput data. For this study we focused on using the Disease (by biomarker) analysis. MetaCore bases disease ontology on classifications in Medical Subject headings. Each disease has a corresponding biomarker gene or sets of genes and p-value statistic based on the probability of a random intersection of two different gene sets. The p-value of the intersection between an experimental gene and ontology is considered as a measure of relevance of said ontology to the experimental dataset.

\section{The Database for Annotation, Visualization and} Integrated Discovery (DAVID)

DAVID is a publically available database (http://david. abcc.ncifcrf.gov) that offers a comprehensive set of functional annotation tools to recognize biological meaning behind list from high through put experiments. For this study we focused on using the disease information in the Genetic Association Database curated within DAVID's functional analysis. The statistics used for predicted disease ontologies are p-values using Fisher's exact test.. Each statistical measure corresponds to the probability of one or more genes overlapping with the predicted disease ontology. 


\section{Additional files}

Additional file 1: Table S1. All differentially expressed genes $(F D R<0.05)$ between $\mathrm{AD}$ and control.

Additional file 2: Table S2. Differentially expressed genes identifying enriched homostatic processes through IPA analysis.

Additional file 3: Table S3. Highly central genes identified through graph theory analysis.

\section{Competing interests}

The authors declare that they have no competing interests.

\section{Authors' contributions}

The study was designed by JMW and HSF. Analysis was carried out by JMW, and interpreted by JMW and HSF. The paper was written by JMW, edited by HSF, and approved by both authors.

\section{Acknowledgements}

This work was supported by NIH grants MH062261 and MH073490, and funds from the Straws Foundation.

Received: 14 November 2012 Accepted: 19 June 2013

Published: 26 June 2013

\section{References}

1. Brookmeyer R, Johnson E, Ziegler-Graham K, Arrighi HM: Forecasting the global burden of alzheimer's disease. Alzheimers Dement 2007 3(3):186-191.

2. Waldemar $G$, Dubois B, Emre M, Georges J, McKeith IG, Rossor M, Scheltens P, Tariska P, Winblad B: Recommendations for the diagnosis and management of alzheimer's disease and other disorders associated with dementia: Efns guideline. Eur J Neurol 2007, 14(1):e1-e26.

3. Spires-Jones T, Knafo S: Spines, plasticity, and cognition in alzheimer's model mice. Neural Plast 2012, 2012:319836.

4. Oddo S, Caccamo A, Kitazawa M, Tseng BP, LaFerla FM: Amyloid deposition precedes tangle formation in a triple transgenic model of alzheimer's disease. Neurobiol Aging 2003, 24(8):1063-1070.

5. Blalock EM, Buechel HM, Popovic J, Geddes JW, Landfield PW: Microarray analyses of laser-captured hippocampus reveal distinct gray and white matter signatures associated with incipient alzheimer's disease. J Chem Neuroanat 2011, 42(2):118-126.

6. Liang WS, Dunckley T, Beach TG, Grover A, Mastroeni D, Walker DG, Caselli RJ, Kukull WA, McKeel D, Morris JC, Hulette C, Schmechel D, Alexander GE, Reiman EM, Rogers J, Stephan DA: Gene expression profiles in anatomically and functionally distinct regions of the normal aged human brain. Physiol Genomics 2007, 28(3):311-322

7. Liang WS, Reiman EM, Valla J, Dunckley T, Beach TG, Grover A, Niedzielko TL, Schneider LE, Mastroeni D, Caselli R, Kukull W, Morris JC, Hulette CM, Schmechel D, Rogers J, Stephan DA: Alzheimer's disease is associated with reduced expression of energy metabolism genes in posterior cingulate neurons. Proc Natl Acad Sci USA 2008, 105(11):4441-4446.

8. Xu PT, Li YJ, Qin XJ, Scherzer CR, Xu H, Schmechel DE, Hulette CM, Ervin J, Gullans SR, Haines J, Pericak-Vance MA, Gilbert JR: Differences in apolipoprotein e3/3 and e4/4 allele-specific gene expression in hippocampus in alzheimer disease. Neurobiol Dis 2006, 21(2):256-275.

9. Parachikova A, Agadjanyan MG, Cribbs DH, Blurton-Jones M, Perreau V, Rogers J, Beach TG, Cotman CW: Inflammatory changes parallel the early stages of alzheimer disease. Neurobiol Aging 2007, 28(12):1821-1833.

10. Katsel P, Tan W, Haroutunian V: Gain in brain immunity in the oldest-old differentiates cognitively normal from demented individuals. PLoS One 2009, 4(10):e7642.

11. Haroutunian $V$, Katsel $P$, Schmeidler J: Transcriptional vulnerability of brain regions in alzheimer's disease and dementia. Neurobiol Aging 2009, 30(4):561-573

12. Katsel P, Li C, Haroutunian V: Gene expression alterations in the sphingolipid metabolism pathways during progression of dementia and alzheimer's disease: A shift toward ceramide accumulation at the earliest recognizable stages of alzheimer's disease? Neurochem Res 2007, 32(4-5):845-856.
13. Youn $H$, Jeoung $M$, Koo Y, Ji H, Markesbery WR, Ji I, Ji TH: Kalirin is under-expressed in alzheimer's disease hippocampus. J Alzheimers Dis 2007, 11(3):385-397.

14. Andrel JA, Keith SW, Leiby BE: Meta-analysis: A brief introduction. Clin Trans/ Sci 2009, 2(5):374-378.

15. Campain A, Yang YH: Comparison study of microarray meta-analysis methods. BMC Bioinforma 2010, 11:408.

16. Murphy D: Gene expression studies using microarrays: Principles, problems, and prospects. Adv Physiol Educ 2002, 26(1-4):256-270.

17. Kong $X$, Mas $V$, Archer $\mathrm{KJ}$ : A non-parametric meta-analysis approach for combining independent microarray datasets: Application using two microarray datasets pertaining to chronic allograft nephropathy. BMC Genomics 2008, 9:98.

18. Braak H, Braak E: Neuropathological stageing of alzheimer-related changes. Acta Neuropathol 1991, 82(4):239-259.

19. Irizarry RA, Warren D, Spencer F, Kim IF, Biswal S, Frank BC, Gabrielson E, Garcia JG, Geoghegan J, Germino G, Griffin C, Hilmer SC, Hoffman E, Jedlicka AE, Kawasaki E, Martinez-Murillo F, Morsberger L, Lee $H$, Petersen D, Quackenbush J, Scott A, Wilson M, Yang Y, Ye SQ, Yu W: Multiple-laboratory comparison of microarray platforms. Nat Methods 2005, 2(5):345-350.

20. Cajigas IJ, Tushev G, Will TJ, Tom Dieck S, Fuerst N, Schuman EM: The local transcriptome in the synaptic neuropil revealed by deep sequencing and high-resolution imaging. Neuron 2012, 74(3):453-466.

21. De Franceschi $L$, Scardoni $G$, Tomelleri $C$, Danek A, Walker $\mathrm{RH}$, Jung $\mathrm{HH}$, Bader B, Mazzucco S, Dotti MT, Siciliano A, Pantaleo A, Laudanna C: Computational identification of phospho-tyrosine sub-networks related to acanthocyte generation in neuroacanthocytosis. PLoS One 2012, 7(2):e31015.

22. Barron AM, Pike CJ: Sex hormones, aging, and alzheimer's disease. Front Biosci (Elite Ed) 2012, 4:976-997.

23. Barbash S, Soreq H: Threshold-independent meta-analysis of alzheimer's disease transcriptomes shows progressive changes in hippocampal functions, epigenetics and microrna regulation. Curr Alzheimer Res 2012, 9(4):425-435.

24. Andersen $K$, Launer $L$, Dewey ME, Letenneur L, Ott A, Copeland JR, Dartigues JF, Kragh-Sorensen P, Baldereschi M, Brayne C, Lobo A, Martinez-Lage JM, Stijnen T, Hofman A: Gender differences in the incidence of ad and vascular dementia: The eurodem studies. Eurodem incidence research group. Neurology 1999, 53(9):1992-1997.

25. Bachman DL, Wolf PA, Linn R, Knoefel JE, Cobb J, Belanger A, D'Agostino RB, White LR: Prevalence of dementia and probable senile dementia of the alzheimer type in the framingham study. Neurology 1992, 42(1):115-119.

26. Brayne C, Gill C, Huppert FA, Barkley C, Gehlhaar E, Girling DM, O'Connor DW, Paykel ES: Incidence of clinically diagnosed subtypes of dementia in an elderly population. Cambridge project for later life. Br J Psychiatry 1995, 167(2):255-262.

27. Farrer LA, Cupples LA, Haines JL, Hyman B, Kukull WA, Mayeux R, Myers RH Pericak-Vance MA, Risch N, van Duijn CM: Effects of age, sex, and ethnicity on the association between apolipoprotein e genotype and alzheimer disease. A meta-analysis. Apoe and alzheimer disease meta analysis consortium. JAMA 1997, 278(16):1349-1356.

28. Fratiglioni L, Viitanen M, von Strauss E, Tontodonati V, Herlitz A, Winblad B: Very old women at highest risk of dementia and alzheimer's disease: Incidence data from the kungsholmen project, stockholm. Neurology 1997, 48(1):132-138.

29. Hagnell O, Ojesjo L, Rorsman B: Incidence of dementia in the lundby study. Neuroepidemiology 1992, 11(Suppl 1):61-66.

30. Jorm AF, Korten $A E$, Henderson AS: The prevalence of dementia: A quantitative integration of the literature. Acta Psychiatr Scand 1987, 76(5):465-479.

31. Molsa PK, Marttila RJ, Rinne UK: Epidemiology of dementia in a finnish population. Acta Neurol Scand 1982, 65(6):541-552.

32. Rocca WA, Amaducci LA, Schoenberg BS: Epidemiology of clinically diagnosed alzheimer's disease. Ann Neurol 1986, 19(5):415-424.

33. Ruitenberg A, Ott A, van Swieten JC, Hofman A, Breteler MM: Incidence of dementia: Does gender make a difference? Neurobiol Aging 2001, 22(4):575-580

34. Callahan MJ, Lipinski WJ, Bian F, Durham RA, Pack A, Walker LC: Augmented senile plaque load in aged female beta-amyloid precursor protein-transgenic mice. Am J Pathol 2001, 158(3):1173-1177. 
35. Hirata-Fukae C, Li HF, Hoe HS, Gray AJ, Minami SS, Hamada K, Niikura T, Hua F, Tsukagoshi-Nagai H, Horikoshi-Sakuraba Y, Mughal M, Rebeck GW, LaFerla FM, Mattson MP, Iwata N, Saido TC, Klein WL, Duff KE, Aisen PS, Matsuoka Y: Females exhibit more extensive amyloid, but not tau, pathology in an alzheimer transgenic model. Brain Res 2008, 1216:92-103.

36. Wang J, Tanila H, Puolivali J, Kadish I, van Groen T: Gender differences in the amount and deposition of amyloidbeta in appswe and ps1 double transgenic mice. Neurobiol Dis 2003, 14(3):318-327.

37. Dubal DB, Shughrue PJ, Wilson ME, Merchenthaler I, Wise PM: Estradiol modulates bcl-2 in cerebral ischemia: A potential role for estrogen receptors. J Neurosci 1999, 19(15):6385-6393.

38. Nilsen J, Diaz Brinton R: Mechanism of estrogen-mediated neuroprotection: Regulation of mitochondrial calcium and bcl-2 expression. Proc Natl Acad Sci USA 2003, 100(5):2842-2847.

39. Pike $\mathrm{CJ}$ : Estrogen modulates neuronal bcl-xl expression and beta-amyloid-induced apoptosis: Relevance to alzheimer's disease. J Neurochem 1999, 72(4):1552-1563.

40. Singer $\mathrm{CA}$, Rogers $\mathrm{KL}$, Dorsa DM: Modulation of bcl-2 expression: A potential component of estrogen protection in nt2 neurons. Neuroreport 1998, 9(11):2565-2568.

41. Stoltzner SE, Berchtold NC, Cotman CW, Pike CJ: Estrogen regulates bcl-x expression in rat hippocampus. Neuroreport 2001, 12(13):2797-2800.

42. Brinton RD, Chen S, Montoya M, Hsieh D, Minaya J: The estrogen replacement therapy of the women's health initiative promotes the cellular mechanisms of memory and neuronal survival in neurons vulnerable to alzheimer's disease. Maturitas 2000, 34(Suppl 2):S35-S52.

43. Nilsen J, Chen S, Brinton RD: Dual action of estrogen on glutamate-induced calcium signaling: Mechanisms requiring interaction between estrogen receptors and src/mitogen activated protein kinase pathway. Brain Res 2002 930(1-2):216-234.

44. Regan RF, Guo Y: Estrogens attenuate neuronal injury due to hemoglobin, chemical hypoxia, and excitatory amino acids in murine cortical cultures. Brain Res 1997, 764(1-2):133-140

45. Singer CA, Figueroa-Masot XA, Batchelor RH, Dorsa DM: The mitogen-activated protein kinase pathway mediates estrogen neuroprotection after glutamate toxicity in primary cortical neurons. J Neurosci 1999, 19(7):2455-2463.

46. Singer CA, Rogers KL, Strickland TM, Dorsa DM: Estrogen protects primary cortical neurons from glutamate toxicity. Neurosci Lett 1996, 212(1):13-16.

47. Singh M, Setalo G Jr, Guan X, Warren M, Toran-Allerand CD: Estrogen-induced activation of mitogen-activated protein kinase in cerebral cortical explants: Convergence of estrogen and neurotrophin signaling pathways. J Neurosci 1999, 19(4):1179-1188.

48. Sastre M, Walter J, Gentleman SM: Interactions between app secretases and inflammatory mediators. J Neuroinflammation 2008, 5:25.

49. Vasto S, Candore G, Listi F, Balistreri CR, Colonna-Romano G, Malavolta M, Lio D, Nuzzo D, Mocchegiani E, Di Bona D, Caruso C: Inflammation, genes and zinc in alzheimer's disease. Brain Res Rev 2008, 58(1):96-105.

50. Behl C, Davis JB, Lesley R, Schubert D: Hydrogen peroxide mediates amyloid beta protein toxicity. Cell 1994, 77(6):817-827.

51. Mark RJ, Hensley K, Butterfield DA, Mattson MP: Amyloid beta-peptide impairs ion-motive atpase activities: Evidence for a role in loss of neuronal ca2+ homeostasis and cell death. J Neurosci 1995, 15(9):6239-6249.

52. Carlson MC, Zandi PP, Plassman BL, Tschanz JT, Welsh-Bohmer KA Steffens DC, Bastian LA, Mehta KM, Breitner JC: Hormone replacement therapy and reduced cognitive decline in older women: The cache county study. Neurology 2001, 57(12):2210-2216.

53. Henderson WW, Paganini-Hill A, Emanuel CK, Dunn ME, Buckwalter JG: Estrogen replacement therapy in older women. Comparisons between alzheimer's disease cases and nondemented control subjects. Arch Neurol 1994, 51(9):896-900.

54. Kawas C, Resnick S, Morrison A, Brookmeyer R, Corrada M, Zonderman A, Bacal C, Lingle DD, Metter E: A prospective study of estrogen replacement therapy and the risk of developing alzheimer's disease: The baltimore longitudinal study of aging. Neurology 1997, 48(6):1517-1521.

55. Paganini-Hill A, Henderson WW: Estrogen deficiency and risk of alzheimer's disease in women. Am J Epidemiol 1994, 140(3):256-261.

56. Paganini-Hill A, Henderson WW: Estrogen replacement therapy and risk of alzheimer disease. Arch Intern Med 1996, 156(19):2213-2217.

57. Tang MX, Jacobs D, Stern Y, Marder K, Schofield P, Gurland B, Andrews H, Mayeux R: Effect of oestrogen during menopause on risk and age at onset of alzheimer's disease. Lancet 1996, 348(9025):429-432.
58. Waring SC, Rocca WA, Petersen RC, O'Brien PC, Tangalos EG, Kokmen E: Postmenopausal estrogen replacement therapy and risk of ad: A population-based study. Neurology 1999, 52(5):965-970.

59. Zandi PP, Carlson MC, Plassman BL, Welsh-Bohmer KA, Mayer LS, Steffens DC Breitner JC: Hormone replacement therapy and incidence of alzheimer disease in older women: The cache county study. JAMA 2002, 288(17):2123-2129.

60. Hogervorst E, Boshuisen M, Riedel W, Willeken C, Jolles J: 1998 curt p. Richter award. The effect of hormone replacement therapy on cognitive function in elderly women. Psychoneuroendocrinology 1999, 24(1):43-68.

61. LeBlanc ES, Janowsky J, Chan BK, Nelson HD: Hormone replacement therapy and cognition: Systematic review and meta-analysis. JAMA 2001, 285(11):1489-1499.

62. Ohkura T, Isse K, Akazawa K, Hamamoto M, Yaoi Y, Hagino N: Evaluation of estrogen treatment in female patients with dementia of the alzheimer type. Endocr J 1994, 41(4):361-371.

63. Sherwin BB: Estrogen and/or androgen replacement therapy and cognitive functioning in surgically menopausal women. Psychoneuroendocrinology 1988, 13(4):345-357.

64. Almeida OP, Lautenschlager NT, Vasikaran S, Leedman P, Gelavis A, Flicker L: A 20-week randomized controlled trial of estradiol replacement therapy for women aged 70 years and older: Effect on mood, cognition and quality of life. Neurobiol Aging 2006, 27(1):141-149.

65. Barrett-Connor E, Kritz-Silverstein D: Estrogen replacement therapy and cognitive function in older women. JAMA 1993, 269(20):2637-2641.

66. Binder EF, Schechtman KB, Birge SJ, Williams DB, Kohrt WM: Effects of hormone replacement therapy on cognitive performance in elderly women. Maturitas 2001, 38(2):137-146.

67. Brenner DE, Kukull WA, Stergachis A, van Belle G, Bowen JD, McCormick WC, Teri L, Larson EB: Postmenopausal estrogen replacement therapy and the risk of alzheimer's disease: A population-based case-control study. Am J Epidemiol 1994, 140(3):262-267.

68. Goebel JA, Birge SJ, Price SC, Hanson JM, Fishel DG: Estrogen replacement therapy and postural stability in the elderly. Am J Otol 1995, 16(4):470-474

69. Henderson WW, Paganini-Hill A, Miller BL, Elble RJ, Reyes PF, Shoupe D, McCleary CA, Klein RA, Hake AM, Farlow MR: Estrogen for alzheimer's disease in women: Randomized, double-blind, placebo-controlled trial. Neurology 2000, 54(2):295-301.

70. Polo-Kantola P, Portin R, Polo O, Helenius H, Irjala K, Erkkola R: The effect of short-term estrogen replacement therapy on cognition: A randomized, double-blind, cross-over trial in postmenopausal women. Obstet Gynecol 1998, 91(3):459-466.

71. Wang PN, Liao SQ, Liu RS, Liu CY, Chao HT, Lu SR, Yu HY, Wang SJ, Liu HC: Effects of estrogen on cognition, mood, and cerebral blood flow in ad: A controlled study. Neurology 2000, 54(11):2061-2066.

72. Yaffe K, Krueger K, Sarkar S, Grady D, Barrett-Connor E, Cox DA, Nickelsen T: Cognitive function in postmenopausal women treated with raloxifene. $N$ Eng J Med 2001, 344(16):1207-1213.

73. Mulnard RA, Cotman CW, Kawas C, van Dyck CH, Sano M, Doody R, Koss E, Pfeiffer E, Jin S, Gamst A, Grundman M, Thomas R, Thal LJ: Estrogen replacement therapy for treatment of mild to moderate alzheimer disease: A randomized controlled trial. Alzheimer's disease cooperative study. JAMA 2000, 283(8):1007-1015.

74. Shao H, Breitner JC, Whitmer RA, Wang J, Hayden K, Wengreen H, Corcoran C, Tschanz J, Norton M, Munger R, Welsh-Bohmer K, Zandi PP: Hormone therapy and alzheimer disease dementia: New findings from the cache county study. Neurology 2012, 79(18):1846-1852.

75. Hestiantoro A, Swaab DF: Changes in estrogen receptor-alpha and -beta in the infundibular nucleus of the human hypothalamus are related to the occurrence of alzheimer's disease neuropathology. J Clin Endocrinol Metab 2004, 89(4):1912-1925.

76. Kalesnykas G, Roschier U, Puolivali J, Wang J, Miettinen R: The effect of aging on the subcellular distribution of estrogen receptor-alpha in the cholinergic neurons of transgenic and wild-type mice. Eur J Neurosci 2005, 21(5):1437-1442.

77. Lu YP, Zeng M, Swaab DF, Ravid R, Zhou JN: Colocalization and alteration of estrogen receptor-alpha and -beta in the hippocampus in alzheimer's disease. Hum Pathol 2004, 35(3):275-280.

78. Boulware MI, Mermelstein PG: The influence of estradiol on nervous system function. Drug News Perspect 2005, 18(10):631-637. 
79. Schupf N, Lee JH, Wei M, Pang D, Chace C, Cheng R, Zigman WB, Tycko B, Silverman W: Estrogen receptor-alpha variants increase risk of alzheimer's disease in women with down syndrome. Dement Geriatr Cogn Disord 2008, 25(5):476-482.

80. Kim H, Bang OY, Jung MW, Ha SD, Hong HS, Huh K, Kim SU, Mook-Jung I: Neuroprotective effects of estrogen against beta-amyloid toxicity are mediated by estrogen receptors in cultured neuronal cells. Neurosci Lett 2001, 302(1):58-62

81. Cordey M, Pike CJ: Neuroprotective properties of selective estrogen receptor agonists in cultured neurons. Brain Res 2005, 1045(1-2):217-223.

82. Zhao L, Brinton RD: Estrogen receptor alpha and beta differentially regulate intracellular $\mathrm{ca}(2+)$ dynamics leading to erk phosphorylation and estrogen neuroprotection in hippocampal neurons. Brain Res 2007, 1172:48-59

83. Zhao L, Wu TW, Brinton RD: Estrogen receptor subtypes alpha and beta contribute to neuroprotection and increased bcl-2 expression in primary hippocampal neurons. Brain Res 2004, 1010(1-2):22-34.

84. Atwood CS, Meethal SV, Liu T, Wilson AC, Gallego M, Smith MA, Bowen RL: Dysregulation of the hypothalamic-pituitary-gonadal axis with menopause and andropause promotes neurodegenerative senescence. J Neuropathol Exp Neurol 2005, 64(2):93-103.

85. Rosario ER, Pike CJ: Androgen regulation of beta-amyloid protein and the risk of alzheimer's disease. Brain Res Rev 2008, 57(2):444-453.

86. Azcoitia I, Sierra A, Veiga S, Honda S, Harada N, Garcia-Segura LM Brain aromatase is neuroprotective. J Neurobiol 2001, 47(4):318-329.

87. Almeida OP, Flicker L: Testosterone and dementia: Too much ado about too little data. J Br Menopause Soc 2003, 9(3):107-110.

88. Gandy S, Almeida OP, Fonte J, Lim D, Waterrus A, Spry N, Flicker L, Martins RN: Chemical andropause and amyloid-beta peptide. JAMA 2001, 285(17):2195-2196

89. Gautier L, Moller M, Friis-Hansen L, Knudsen S: Alternative mapping of probes to genes for affymetrix chips. BMC Bioinforma 2004, 5:111.

90. Prieto C, Risueno A, Fontanillo C, De Las Rivas J: Human gene coexpression landscape: Confident network derived from tissue transcriptomic profiles. PLoS One 2008, 3(12):e3911.

91. Risueno A, Fontanillo C, Dinger ME, De Las Rivas J: Gatexplorer: Genomic and transcriptomic explorer; mapping expression probes to gene loci, transcripts, exons and ncrnas. BMC Bioinforma 2010, 11:221.

92. Bolstad BM, Irizarry RA, Astrand M, Speed TP: A comparison of normalization methods for high density oligonucleotide array data based on variance and bias. Bioinformatics 2003, 19(2):185-193.

93. Hong F, Breitling R, McEntee CW, Wittner BS, Nemhauser JL, Chory J: Rankprod: A bioconductor package for detecting differentially expressed genes in meta-analysis. Bioinformatics 2006, 22(22):2825-2827.

94. Berger SI, Posner JM, Ma'ayan A: Genes2networks: Connecting lists of gene symbols using mammalian protein interactions databases. BMC Bioinforma 2007, 8:372.

95. Smoot ME, Ono K, Ruscheinski J, Wang PL, Ideker T: Cytoscape 2.8: New features for data integration and network visualization. Bioinformatics 2011, 27(3):431-432.

96. Scardoni G, Petterlini M, Laudanna C: Analyzing biological network parameters with centiscape. Bioinformatics 2009, 25(21):2857-2859.

97. Bader GD, Hogue CW: An automated method for finding molecular complexes in large protein interaction networks. BMC Bioinforma 2003, 4:2.

Cite this article as: Winkler and Fox: Transcriptome meta-analysis reveals a central role for sex steroids in the degeneration of hippocampal neurons in Alzheimer's disease. BMC Systems Biology 2013 7:51.

\section{Submit your next manuscript to BioMed Central and take full advantage of:}

- Convenient online submission

- Thorough peer review

- No space constraints or color figure charges

- Immediate publication on acceptance

- Inclusion in PubMed, CAS, Scopus and Google Scholar

- Research which is freely available for redistribution

Submit your manuscript at www.biomedcentral.com/submit
Ciomed Central 